\title{
Drillstring Failure: Analytical and Experimental Approach
}

\author{
Edris Hassan ${ }^{1,1}$, Jamil $\mathrm{Abdo}^{2}$, Jan $\mathrm{Kwak}^{3}$, and Abdullah Al Shabibi ${ }^{1}$ \\ ${ }^{1}$ Department of Mechanical and Industrial Engineering, College of Engineering, Sultan Qaboos \\ University, Muscat, Oman \\ ${ }^{2}$ Department of Mechanical and Aerospace Engineering, Utah State University, Logan, UT, USA \\ ${ }^{3}$ Department of Chemistry and Earth Sciences, College of Science, Qatar University, Doha, Qatar
}

\begin{abstract}
Drilling is one of the costliest activities in oil and gas industry due to the complexity of interactions with downhole rock formation. Under such conditions, the uncertainty of drillstring behaviour increase and hence it becomes difficult to predict the causes, occurrences, and types of failures. Lateral and torsional vibrations often cause failure of Bottom Hole Assembly (BHA), drillstring failure, drill bit and wall borehole damages. In this work, a model is presented to determine the impact of lateral and torsional vibrations on a drillstring during the drilling operation. The model aims to mimic real drillstring behaviour inside a wellbore with regards to its dynamic movements due to multiple real situations such as eccentricity of collars, drill pipe sections, and stick-slip phenomena occurring due to the interaction of the bit and the drillstring with the well formation. The work aims to develop a basis for determining critical operating speeds and design parameters to provide safe drilling procedures and reduce drill string fatigue failure. Lagrangian approach is used in this study to attain drillstring lateral and torsional vibration coupling equations. The nonlinear equations are solved numerically to obtain the response of the system. In this work, we also present a brief description of an in-house constructed experimental setup. The setup has the capability to imitate the downhole lateral and torsional vibration modes. Parameters from the experimental investigations are incorporated for validation of the mathematical models and for prediction of the drillstring fatigue life. Such investigations are essential for oil and gas industries as they provide solutions and recommendations about operational speed, lateral and torsional amplitudes measurements and corrections, and the conditions for avoiding occurrence of natural frequencies of the system.
\end{abstract}




\section{Introduction}

In drilling of oil and gas wells, severe shock and vibrations occur that are detrimental to the service life of drillstrings and down-hole assembly tools. The causes of these vibrations are due to complex surroundings and a lot of uncertainties include impact and friction at the interfaces of borehole/drillstring and bit/ hard-rock formation, imbalances, drillstring eccentricity or initial curvature in the drill collar sections, various linear or non-linear resonances [1-3]. There are three modes of vibration mainly axial, lateral, and torsional, which indicate direction and response of the drillstring when it runs into trouble downhole [4]. Drillstring fatigue failure is very common due to generation of single and coupled vibration modes and mechanisms. These severe vibrations often cause failures of BHA tool, drill pipe abrasive wear, drill bit and wall borehole damages, reduction of the rate of penetration (ROP), and consequently incur high costs [5-6].

Several attempts have been made to study the drillstring vibrations and to overcome the difficulties encountered by field engineers. Laboratory testing to investigate lateral behaviour of a part of a drillstring represented by a rod and subjected to axial loading was highlighted in [7]. The experimental set-up takes into account the curvature of the rod, mud, stabilizers and rotational speed. The lateral behaviour of the drill string subjected to axial excitations of the drill bit is governed by time varying parameter equations due to torsion-lateral and longitudinal-lateral couplings. The dynamic stability of drill strings has been studied by Yigit and Christofourou [8]. In their study transverse vibrations induced by axial loading in a drill string modeled by a uniform slender beam undergoing axial and transverse deformations. Non rotating drill strings are considered and all deformations are assumed to occur in a single plane. The transverse motion of the beam is conned by the borehole and is assumed to be adequately modeled by Euler-Bernoulli beam theory. In the problem formulation, linear and nonlinear coupling were retained which leads to fully coupled differential equations. A method was suggested in [9] to examine some of the drilling technology factors that can affect drill string fatigue behaviour. Such drilling technology factors include tensile load, torque, abrasive wear and mud corrosion. Alternative approximate techniques to determine the amplitudes of the limit cycles that evolve from stick-slip vibrations were carried out in [10]. Approximate closed-form equations were derived for normal and tangential contact forces of rough surfaces in dry friction in [11].

Some other approaches were suggested for the analysis of some of the drilling technology factors that can affect the drilling string fatigue behaviour. Comparative study of full-scale fatigue test results and field data were accordingly presented in [12-14]. Such drilling factors include threaded connections. A full scale mathematical modeling to predict fatigue life in a threaded connection is proposed in [15].

This paper aims at gaining deeper understanding of the complex behaviour of drillstring under vibrations and its detrimental effect on drilling operation. The Lagrangian approach is used to obtain the drill pipe lateral and torsional vibration coupling equations of motion. The mathematical model is expressed in terms of four independent degrees of freedom. The effects of bending and torsion vibrations, and whirling motion of the drillstring are included in the model. The nonlinear equations are solved numerically to obtain the response. The experimental setup provides further development of a more comprehensive testing of drillstring.

\section{Analytical Approach}

In this work a mathematical model that accounts for the effects of lateral and torsional vibrations on a drillstring generated due to the interaction of the drillstring with the formation during the drilling operation is formulated. Modeling of such rotating component is highly 
non-linear and complex due to contact behavior and dynamics of the drillstring which involve broad vibration profiles include axial, lateral and torsional modes. In such a problem, it is convenient to model it as a simple Jeffcott rotor model. The Jeffcot rotor model is capable of retaining crucial characteristics of a rotor in its imbalance response. A schematic diagram of the unbalanced mass and rotor system is shown in Fig. 1. The model consists of two rigid frictionless bearings, an elastic isotropic shaft, and a rigid disk located at the center of the shaft. The proposed model imitates the built-in experimental setup and captures its dynamic response for different system's parameters.

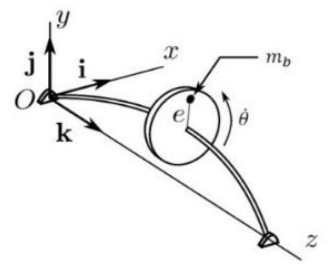

Fig. 1. Representation diagram for the equivalent model

In the proposed model, an unbalance mass $m_{b}$ is attached to the rotor of mass $M$ and mass moment of inertia $I_{o}$ at distance e represent eccentricity with respect to its geometrical centre. The lumped parameter model is shown in Fig. 2. The rotor is assumed to be symmetrical such that the lateral stiffnesses and lateral damping have an equivalent spring constants and damping coefficients of $k_{x}=k_{y}=k_{b}$ and $c_{x}=c_{y}=c_{b}$, respectively. Torsional motion is represented by dissipating and conservative components defined by the damping coefficient $c_{\text {tor }}$ and the spring constant $k_{\text {tor }}$. The degrees of freedom can be described by three orthogonal unit vectors, namely, $\left(a_{1}, a_{2}\right),\left(b_{1}, b_{2}\right)$ and $\left(c_{1}, c_{2}\right)$. The unit vectors are projected into $\mathrm{x}$ and $\mathrm{y}$ coordinates and fixed at the origin O. Both $\left(b_{1}, b_{2}\right)\left(c_{1}, c_{2}\right)$ unit vectors are fixed at the geometrical centre of the rotor and allowed to rotate. The reference frame $\left(b_{1}, b_{2}\right)$ is allowed to rotate at a constant angular speed $(\theta)$ with respect to $\left(a_{1}, a_{2}\right)$ reference frame. Therefore, the angle between $a_{l}$ and $b_{l}$ defines rigid body rotation $\theta$. The torsional deformation $(\gamma)$ is defined as the angle between $b_{1}$ and $c_{1}$. In this setting, when the rotor is at rest, all unit vectors coincide. Once a drive speed $(\theta)$ is introduced, the rotor moves away from the origin $O$ due to the effect of the centrifugal force acting on it. As a result, the rotor's geometrical centre is displaced to the point $(\tilde{x}, \tilde{y})$.
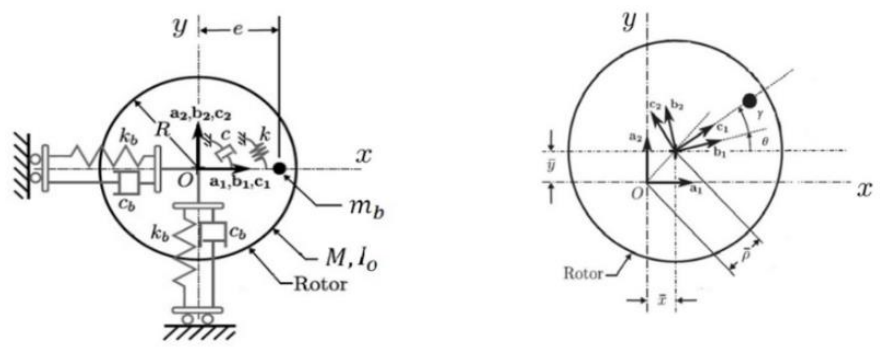

Fig. 2. Lumped parameter model

In addition, it is assumed that the rotor is only able to undergo planar motions with no gyroscopic effects due to rotations about the $x$ and $y$ axes. A constraint is imposed as $a 3=b_{3}$ $=c_{3}$ at the entire time $t$, where $a_{3}=a_{1} \times a_{2}, b_{3}=b_{1} \times b_{2}$ and $c_{3}=c_{1} \times c_{2}$. In order to retain generality, eccentricity is $(e)$ initially parallel to the $x$-axis.

\subsection{Equations of Motion}

There are mainly three approaches that could be used to derivate the governing equations of a dynamic system, namely, the Hamilton's principle, the Lagrange principle or the direct 
equilibrium using d' Alembert's principle. In modeling of drillstring it is simpler to consider energy principal as energy is a scalar quantity, independent on the choice of coordinate system and can easily deal with multi-degrees of freedom systems with the help of the generalized coordinates which describe the system. This, in this work, the Lagrange's equation is used to derive the system's equations of motion.

$$
\begin{gathered}
L=T-U \\
\frac{d}{d t}\left(\frac{\delta L}{\delta \dot{q}_{i}}\right)-\frac{\delta L}{\delta q_{i}}+\frac{\delta D}{\delta \dot{q}_{i}}=F_{i}
\end{gathered}
$$

where:

$q_{i}$ : generalized coordinate (Degree of Freedom).

$D$ : Rayleigh dissipation function.

$F_{i}$ : generalized force along a particular generalized coordinate.

\subsection{Kinetic and Potential Energies}

The Kinetic energy of the system can be written as:

$$
T_{\text {total }}=T_{M}+T_{b}
$$

where:

$T_{M}$ : Kinetic energy of the rotor.

$T_{b}$ : Kinetic energy of the unbalance mass. Hence

and,

$$
T_{M}=\frac{1}{2} M\left(\dot{x}^{2}+\dot{y}^{2}\right)+\frac{1}{2} I_{o}(\dot{\theta}+\dot{\gamma})^{2}
$$

$$
T_{b}=\frac{1}{2} m_{b} v_{b}^{2}
$$

where:

$v_{b}$ : unbalanced mass velocity.

the position of the unbalance mass at an instant can be written as:

Then the $T_{\text {total }}$ can be written as:

$$
\overrightarrow{x_{b}}=[x+e \cos (\theta+\gamma)] i+[y+e \sin (\theta+\gamma)] j
$$

$$
\begin{aligned}
T_{\text {total }}=\frac{1}{2} M\left(\dot{x}^{2}+\dot{y}^{2}\right) & +\frac{1}{2} I_{o}(\dot{\theta}+\dot{\gamma})^{2} \\
& +\left(\frac{1}{2} m_{b}\right)\left[\{\dot{x}-e(\dot{\theta}+\dot{\gamma}) \sin (\theta+\gamma)\}^{2}\right. \\
& +\left\{(\dot{y}+e(\dot{\theta}+\dot{\gamma}) \cos (\theta+\gamma)\}^{2}\right]
\end{aligned}
$$

The system's total potential energy can be divided into three terms, namely, $U_{x}, U_{y}$ and $U_{\text {tor }}$. Where $U_{x}, U_{y}$ and $U_{t o r}$ are the potential energies along the $x, y$ and torsional direction, respectively. Therefore, the total potential energy can be written as follows:

$$
U_{\text {total }}=U_{x}+U_{y}+U_{\text {tor }}
$$

Utilizing the Lagrange formulation in three degrees of freedom given in Eq. 5 and the set of equations for kinetic and potential energies, yield the following three equations of motion for the system:

$$
\begin{aligned}
& \left(M+m_{b}\right) \ddot{x}+c_{b} \dot{x}+k_{b} x=m_{b} e\left[(\ddot{\theta}+\ddot{\gamma}) \sin (\theta+\gamma)+(\dot{\theta}+\dot{\gamma})^{2} \cos (\theta+\gamma)\right] \\
& \left(M+m_{b}\right) \ddot{y}+c_{b} y+k_{b} y=m_{b} e\left[(\dot{\theta}+\dot{\gamma})^{2} \sin (\theta+\gamma)-(\ddot{\theta}+\ddot{\gamma}) \cos (\theta+\gamma)\right] \\
& I \ddot{\gamma}+c_{t o r} \dot{\gamma}+k_{t o r} \gamma=m_{b} e[(\ddot{x} \sin (\theta+\gamma))-(\ddot{y} \cos (\theta+\gamma))]+T_{\text {tor }}
\end{aligned}
$$

where, $I=I_{o}+m_{b} e^{2}$ 
Eqs. (9-11) are nonlinear ordinary differential equations. These set of equations were solved numerically using fourth-order Runge-Kutta Algorithm in Matlab software. The outcome of applying this Algorithm is presented in the results and discussion section.

\section{Experimental Approach}

A novel in-house experimental setup capable of imitating downhole lateral and torsional vibrations has been designed and constructed. In this work, vibration coupling effects and interactions between various phenomena such as whirling, and parametric excitation are investigated. Parameters of experimental setup have been adopted to validate the previously developed mathematical model. This helps reducing drillstring failures as well as provides satisfactory answers and justifications about uncertainty and performance of the drillstring under various loading and operating conditions. Fig. 3 (a, b) shows the experimental setup and schematic of the setup and its individual components. Table 1 lists representations for the numbers of components. Fig. $4(\mathrm{a}, \mathrm{b})$ shows torque measurement system fixed to the drillstring and the induced lateral vibration is represented by an eccentric mass. To induce torsional vibration, a braking mechanism is adopted. In this work, the breaking mechanism is constrained to brake at fixed duration and steady applied torque while allowing multiple numbers of brakes.
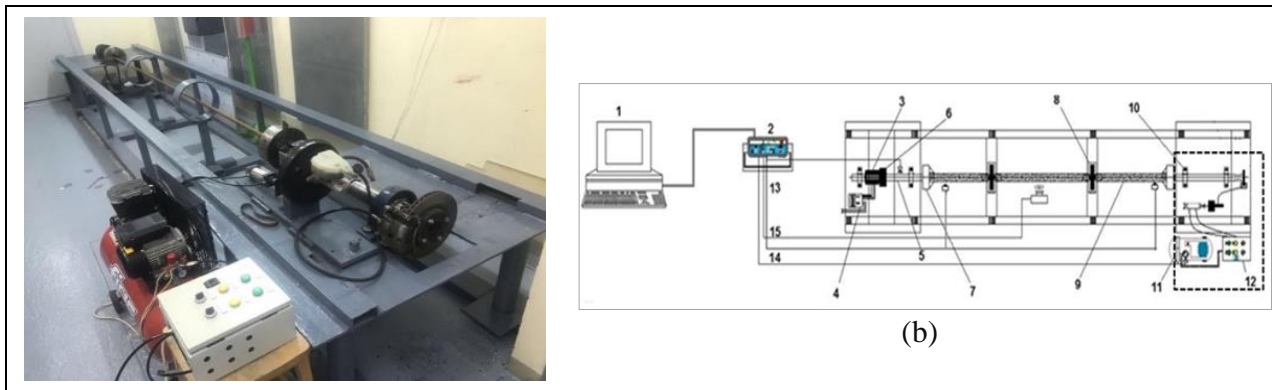

(b)

(a)

Fig. 3. Experimental Setup (a) and its individual components schematics (b)

Table 1: Main components of the experimental setup

\begin{tabular}{|c|c|}
\hline $\begin{array}{c}\text { COMPONENTS/ } \\
\text { SYSTEMS }\end{array}$ & PART NAME \\
\hline 1 & Computer \\
\hline 2 & Data acquisition system \\
\hline 3 & Splase electrical motor \\
\hline 4 & Shaft \\
\hline 5 & Sprocket and Chain \\
\hline 6 & Specimen (Tube) \\
\hline 7 & Ball bearing \\
\hline 8 & Compressor \\
\hline 9 & Brake system controller \\
\hline 10 & Hall effect sensor \\
\hline 11 & Brake on/off switch \\
\hline 12 & Ultrasonic sensor \\
\hline 13 & Torque Measurement System \\
\hline 14 & \\
\hline 15 & \\
\hline 16 & \\
\hline & \\
\hline
\end{tabular}




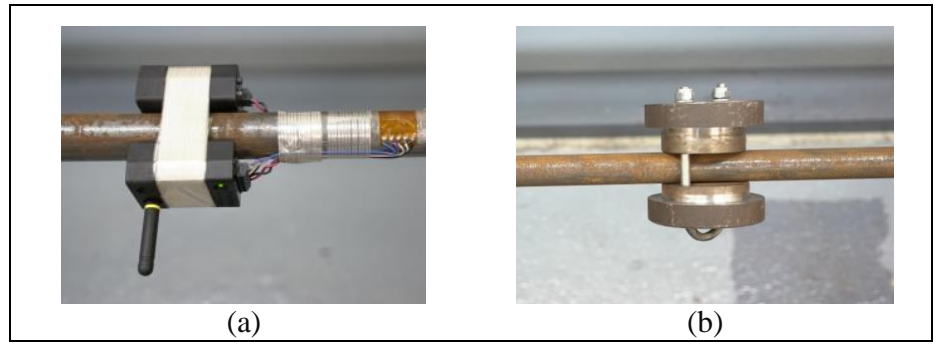

Fig. 4. Torque measurement system (a) and Unbalanced mass

\section{Results and Discussions}

\subsection{Parameters and Results of the Mathematical Approach}

\subsubsection{Undamped rotor rotating at critical speed:}

The undamped system is examined and shown that the critical speed occurs when $\dot{\theta}=w_{n, b}$. and $c_{b}=$ 0 . Fig. 5 (a) shows that lateral deflections are continuously increased as undamped system is operated at its critical speed. Hence, rotating close to its critical speed maximum values of deflections are reached. Fig. 5 (b) shows trajectories of horizontal and vertical deflections of undamped shaft rotating at critical speed.

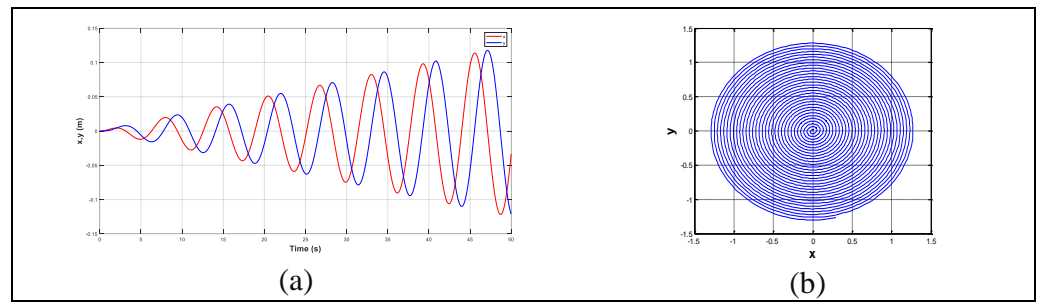

Fig. 5. Undamped system lateral deflections (a) and trajectories horizontal and vertical deflections of undamped shaft (b).

\subsubsection{Effect of Bending damping ratio on rotor's response}

The effect of bending damping ratio on the rotor's response was investigated by changing the value of the damping coefficient. The effects of changing damping ratio $\left(\zeta_{b}=0.05,0.07 \& 0.1\right)$ on transient response and magnitude of deflection were observed. It is lengthy to reproduce complete results here. A representative trend is depicted in Fig. $6(\mathrm{a}, \mathrm{b})$. Increasing the bending ratio, the time required to reach steady state response and deflections are reduced. This is due to the increase in the dissipated energy of the system.

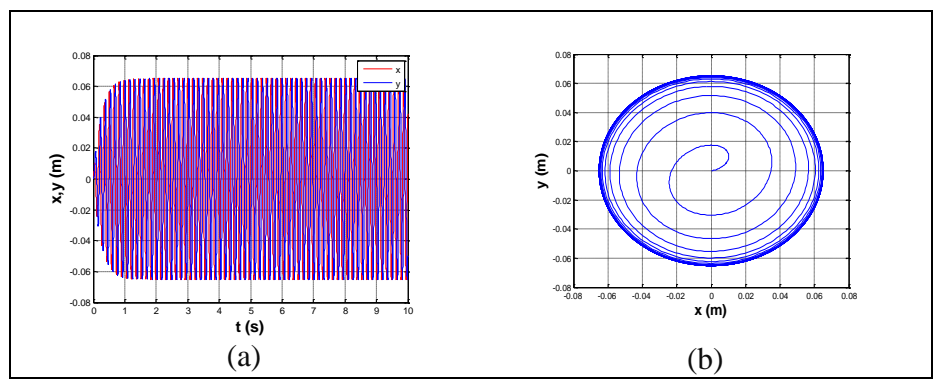

Fig. 6. Effects of changing damping ratio at $\zeta_{b}=0.1$ on deflections (a) and trajectories (b).

Three other important effects include $(i)$ the effect of unbalanced mass on the rotor's response, (ii) the effect of bending damping ratio on the rotor's response due to change in 
damping coefficients and (iii) the effect of reverse torque on the rotor's response were all thoroughly investigated. The reader may refer to the authors study [16].

\subsection{Experimental results}

The experiments were carried out under controlled conditions to examine the setup performance, and to investigate the effects of induced lateral vibration on the drill string fatigue failure. Sets of drill strings of 1", 2" and 3" outer diameter and $5 \mathrm{~m}$ long were used. Initial tests were performed by rotating the drillstring on various rotational speed and lateral amplitudes were observed. Fig. 7 shows the rotational speed vs. lateral deflections for the three drillstrings. It shows that the amplitudes are lower in larger drillstring diameters at same rotational speed. In addition, the lateral amplitude is higher for higher speed for the same drillstring dimensions.

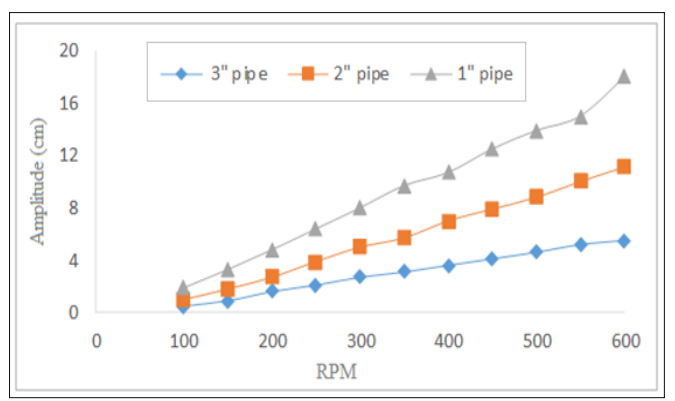

Fig. 7. Drillstrings behavior at various rotational speeds

Fig. 8 illustrates that the maximum lateral amplitude occurs in the middle of the drillstring. Lateral vibration in a drillstring often results from eccentricity which leads to centripetal forces at particular rotational speeds. When external excitations (rotating the drillstring) take place close to lateral natural frequencies, the amplitude of lateral vibration remarkably increases and hence the drillstring strikes wellbore wall and creates considerable shocks.

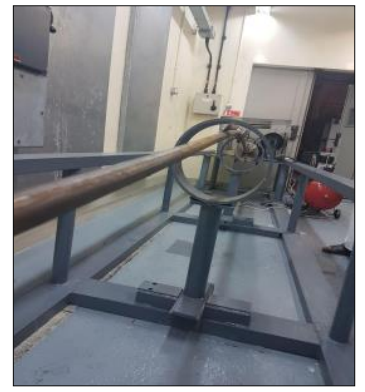

Fig. 8. Large lateral amplitude for 1" drillstring near its rotational critical speed.

\section{Conclusions}

This work aimed at gaining a deeper understanding of the complex behavior of drillstring under vibrations and its detrimental effect on drilling operation. The developed model imitates real drillstring behavior inside the wellbore with regards to its dynamic movements based on modeling an in-house constructed testing rig which mimic the real drilling field operations. The Lagrangian approach is used to obtain the drillstring lateral and torsional vibration coupling equations of motion. A mathematical model is developed to simulate the dynamic behavior of the drillstring. The effects of lateral and torsional vibrations and whirling motion of the drillstring are included in the model. An experimental setup was developed to imitate the vibration modes induced in the drillstring when it runs downhole in 
oil or gas wells. The testing facility is capable of investigating effects of individual and coupled modes on vibration on drill string failure. Results showed that the lateral amplitude versus number of stress cycles behavior is similar to the familiar fatigue S-N curve. Torsional vibration is induced in the drillstring by applying a constant reversed torque utilizing the braking mechanism in the drillstring at multiple numbers of brakes. Results showed that multiple numbers of braking, which represent frequent stick-slip, leads to fatigue failure unless the system's critical operating speeds and design parameters are determined and implemented for a safe drilling. The developed model predicted that the vibrations induced in the drillstring due to the interaction with the wellbore are the main reason for drillstring failure. Established models provides a basis for understanding fatigue failure and leads to prediction of safe operation and long service life of drillstrings.

\section{References}

1. Macdonald, K.A., Bjune, J.V., 2007, "Failure analysis of drillstrings," Engineering Failure Analysis, 14, pp. 1641-1666.

2. Moradi, S., Ranjbar, K., 2009, "Experimental and computational failure analysis of drillstrings. Engineering Failure Analysis," 16, pp. 923-933.

3. Reid, D., Rabja, H., 1995, "Analysis of drill string failure," Presented in 1995 SPE drilling conference, Amsterdam.

4. Jardine, S., Malone, D., Sheppard, M., 1994, "Putting a damper on drilling's bad vibrations," Oilfield Review, 1, pp. 15-20.

5. Spanos, P.D., Chevallier, A.M., Politis, N.P., Payne, M.L., 2003, "Oil well drilling: a vibrations perspective,” The Shock and Vibration Digest, 35(2), pp. 81-99.

6. Khulief, Y.A., Al-Naser, H., 2005, "Finite element dynamic analysis of drill strings," Finite Element Analysis and Design, 41, pp. 1270-1288.

7. Berlioz, A., Der Hagopian, J., Dufour, R, Draoui, E., 1996, "Dynamic behaviour of drillstring: experimental investigation of lateral instabilities," Transaction of the American Society of Mechanical Engineers, Journal of Vibration and Acoustics, 118(3), pp. 292298.

8. Yigit, A.S., Christofourou, A.P., 1996, "Coupled axial and transverse vibrations of oil well drillstrings," Journal of Sound and Vibration, 195(4), pp. 617-627.

9. Baryshnikoy, A., Calderoni, A., Ligrone, A., Ferrara, P., 1997, "A new to the analysis of drillstring fatigue behaviour," SPE Drilling and Completion, 12(2), pp. 77-84.

10. Abdo, J., 2011, "Analytical approach to estimate amplitude of stick-slip oscillations," Journal of Theoretical and Applied Mechanics, 49(4), pp 971-986.

11. Farhang, K., Lim, A., 2007, "A kinetic friction model for viscoelastic contact of nominally flat rough surfaces," Journal of Tribology, 129 (3), pp. 684-688.

12. Yigit, A.S., Christoforou, A.P., 1998. Coupled torsional and bending vibrations of drillstrings subject to impact with friction. Journal of Sound and Vibration. 215(1), 167181.

13. Ghasemloonia, A., Rideout, D.G., Butt, S.D., 2015. A review of drillstring vibration modeling and suppression methods. Journal of Petroleum Science and Engineering. 131(1), 150-164.

14. Abdo, J., 2006, "Modelling of Frictional Contact Parameters of a Mechanical Systems," International Journal of Applied Mechanics and Engineering, 11(3), pp 449-465.

15. J. Abdo, E. Hassan, A. Al-Shabibi and J. Kwak (2017) "Design of a Testing Facility for Investigation of Drill Pipes Fatigue Failure" The Journal of Engineering Research V. 14 (2), p 1-7.

16. J. Abdo, E. Hassan, K. Boulbrachene and J. Kwak (2018), "Drillstring FailureIdentification, Modeling and Experimental Characterization", ASCE-ASME J. of Risk and Uncertainty in Eng. Systems 